\title{
Prediction of asphaltene precipitation upon injection of various gases at near-wellbore conditions: A simulation study using PC-SAFT EoS
}

\author{
Saba Mahmoudvand ${ }^{1}$, Behnam Shahsavani ${ }^{2}$, Rafat Parsaei ${ }^{1, *}$, and Mohammad Reza Malayeri ${ }^{2,3}$ \\ ${ }^{1}$ Department of Petroleum Engineering, School of Chemical and Petroleum Engineering, Shiraz University, 71348-51154 Shiraz, Iran \\ ${ }^{2}$ Enhanced Oil Recovery (EOR) Research Centre, IOR/EOR Research Institute, Shiraz University, 71348-51154 Shiraz, Iran \\ ${ }^{3}$ Institut für Verfahrenstechnik und Umwelttechnik, Technische Universität Dresden, 01062 Dresden, Germany
}

Received: 8 March 2019 / Accepted: 29 May 2019

\begin{abstract}
The depletion of oil reservoirs and increased global oil demand have given impetus to employ various secondary and tertiary oil recovery methods. Gas injection is widely used in both secondary and tertiary modes, though the major problem associated with this process is the precipitation and deposition of asphaltene, particularly at near-wellbore conditions. In-depth knowledge of asphaltene phase behavior is therefore essential for the prediction of asphaltene precipitation. Previous studies reported the impact of gas injection on asphaltene phase behavior, but the knowledge of precipitation of asphaltene as a function of different mole fractions of injected gas is also imperative. In this study, the thermodynamic model of PC-SAFT EoS is used to discern the phase equilibrium of asphaltene by analyzing the asphaltene drop-out curve during gas injection. Asphaltene drop-out curves of two different live oil samples are analyzed by injecting $\mathrm{CO}_{2}, \mathrm{CH}_{4}$, and $\mathrm{N}_{2}$ gases at different mole percentages and temperatures. The results revealed that PC-SAFT EoS can serve as a reliable tool for estimating bubble pressure and asphaltene onset pressure for a wide range of temperatures, pressures, and compositions. The simulation results for the injection of $\mathrm{CO}_{2}, \mathrm{CH}_{4}$, and $\mathrm{N}_{2}$ also showed that $\mathrm{CO}_{2}$ gas gives minimum asphaltene precipitation. It reduces the size of the drop-out curve or moves it toward higher pressures. $\mathrm{CH}_{4}$ and $\mathrm{N}_{2}$ expand the drop-out curve by raising the upper onset point. $\mathrm{CH}_{4}$ increases the maximum point of the drop-out curve for two types of oil studied (A and B) at two different temperatures. $\mathrm{N}_{2}$ raises the maximum point of oil type "A" by approximately $57 \%$ at $395 \mathrm{~K}$, while it has no effect on the maximum point of oil type "B". In addition, reducing the temperature resulted in either decrease or increase of asphaltene solubility, demonstrating that the impact of temperature on asphaltene precipitation is closely related to the composition of the crude.
\end{abstract}

\section{Nomenclature}

$\tilde{a} \quad$ Reduced Helmholtz free energy, $(-) \quad X$

$d_{\mathrm{i}} \quad$ Temperature-dependent segment diameter of component $i, \AA$

$g^{\text {hs }} \quad$ Hard-sphere radial distribution function, $(-)$

$\bar{m} \quad$ Mean segment number, $(-)$

$m_{\mathrm{i}} \quad$ Number of segments in a chain of component i

$U^{\mathrm{r}} \quad$ Residual internal energy, $\mathrm{J}$

$v_{\mathrm{m}} \quad$ Molar volume, $\mathrm{cm}^{3} /$ mole

A Helmholtz free energy, $\mathrm{J}$

$N \quad$ Total number of molecules, $(-)$

$T \quad$ Absolute temperature, $\mathrm{K}$
$Z \quad$ Compressibility factor, $(-)$

$X \quad$ Mole fraction, $(-)$

$\varepsilon^{\mathrm{AB}} \quad$ Association energy between site $A$ and site $B, \mathrm{~J}$ $\kappa^{\mathrm{AiBi}} \quad$ Association volume parameter, $(-)$

$\xi_{n} \quad$ Abbreviation $(n=0, \ldots, 3)$ defined by equation (7), $\AA^{\mathrm{n}-3}$

Fugacity coefficient of component $k,(-)$

Aromaticity value

Hildebrand solubility parameter, $\left(\mathrm{J} / \mathrm{cm}^{3}\right)^{0.5}$

Depth of square well potential, $\mathrm{J}$

Packing fraction, (-)

Boltzmann's constant, $\mathrm{J} / \mathrm{K}$

Total number density of molecules, $1 / \AA$

Temperature independent segment diameter, $\AA$

* Corresponding author: rparsaei@shirazu.ac.ir 


\section{Superscripts}

disp Contribution due to dispersive attraction

hc Hard-chain system residual contribution

hs Hard-sphere system residual contribution

res

Residual contribution

\section{Abbreviations}

APE Asphaltene Phase (or precipitation) Envelope

AARD Absolute Average Relative Deviations

CED Cohesive Energy Density

$\mathrm{Pb} \quad$ Bubble Point Pressure

PL Lower Onset Pressure

PU Upper Onset Pressure

RR Rachford-Rice

\section{Introduction}

Asphaltene is the heaviest and the most polar component of crude oil. Currently, the most common definition of asphaltene is based on its solubility. Asphaltene is soluble in aromatic solvents like benzene, toluene and insoluble in light-paraffinic solvents such as $n$-pentane or $n$-heptane. Asphaltene is also composed of complex poly-nuclear aromatic components, which include alkyl groups. It consists primarily of oxygen, nitrogen, sulfur and metals such as vanadium, and nickel [1-6]. Asphaltene molecule is very complex and its properties would profoundly vary from one crude to another [7]. To recognize asphaltene properties in molecular level several technologies such as field-ionization mass spectrometry [8], electrospray ionization, Fourier transform ion cyclotron resonance mass spectrometry [9], atmospheric pressure photoionization mass spectrometry [10], field-desorption/field ionization mass spectrometry [11], laser desorption ionization [12], and time-resolved fluorescence depolarization [7] are employed nowadays. Exploiting these techniques in the last decade has provided us with a clearer perspective of asphaltene. For instance, these methods give an average molecular weight of about $750 \mathrm{~g} / \mathrm{mol}$ for asphaltene within a range of 300-1400 g/mol [13]. However, large molecular weights reported for asphaltenes in some older reports by vapor pressure osmometry or size exclusion chromatography are most likely due in part to the measurement of aggregate weight, not molecular one.

Asphaltene can cause severe problems in various sectors of the oil industry from reducing the reservoir permeability to plugging the respective facilities such as wellheads, separators, and pipelines [14, 15]. Different mechanical and chemical methods have been proposed for mitigation of asphaltene deposition, but these methods are costly. On the other hand, some of the damages caused by asphaltene are permanent, thus prevention of asphaltene precipitation and deposition are more critical than repairing facilities $[16,17]$. In addition, the removal of asphaltene from the reservoir rock surface is even more complex than the surface facilities. Accordingly, the knowledge of asphaltene behavior, as well as developing a tool to predict its precipitation are essential [2, 18]. It is also known that asphaltene precipitation would precede the deposition but there are other factors involved in this phenomenon such as flow regime, rheology, two-phase flow patterns, and surface characteristics $[5,19,20]$. When the condition changes and asphaltene is no longer soluble in the oil phase, it starts to precipitate from reservoir fluid which would, in turn, increase the oil density. In later stages, the precipitated particles may deposit on the rock surface, which causes pore plugging and formation damage.

The most important step in developing a tool for prediction of asphaltene deposition is an accurate estimation of asphaltene precipitation onset. This is commonly evaluated by thermodynamic models. Asphaltene thermodynamic models are classified into two main categories namely, solubility and colloidal models. In the colloidal approach, the crude is divided into the polar and non-polar subsets. Models based on the colloidal approach assume asphaltenes as suspended solid particles, which are peptized by resins in a colloidal system [21]. This approach assumes that asphaltenes exist in the oil as solid particles; and, describes the stability of asphaltenes in terms of micelle formation where asphaltene self-associates into aggregates to make a core. Then, resins adsorb onto the core (based on polarpolar interactions) to form a steric shell. Asphaltene colloidal stability was first introduced by Nellsteyn and then was modified by Pfeiffer and Saal [22]. While colloidal models of asphaltene were beneficial in the early stages of understanding asphaltene behavior, but they cannot describe reversibility of asphaltene precipitation. Although numerous works have been done using this model and several modifications have been implemented, the colloidal models require many parameters to be tuned prior to prediction [23-26].

Solubility theory assumes asphaltene molecules as part of the oil mixture and asphaltene precipitation is modeled as a liquid-liquid or solid-liquid equilibrium [27]. In this approach, solution theories and Equations of State (EoS) are the two main parts of solubility theory [28-31]. In particular, cubic EoS is used to describe asphaltene phase behavior since it provides a reliable match with the experimental results although its prediction of liquid-liquid equilibrium is questionable [32]. Furthermore, the cubic EoS contains many parameters, which make the calculations tedious and time-consuming [32].

Association EoS such as CPA and SAFT can be used for modeling complex fluid phase behavior like mixtures containing asphaltene. By extending Wertheim's first order perturbation theory to chain molecules, the statistical association fluid theory equation of state was developed by Chapman et al. [33]. Among different modifications of SAFT EoS, PC-SAFT EoS was developed by Gross and Sadowski [34] to account for the chain length effects. This EoS is reported to accurately model different mixtures (containing hydrogen bond mixtures) and pure compounds [34].

Many researchers have modeled asphaltene phase behavior using PC-SAFT EoS. They investigated the effects of injection of different gases on asphaltene phase 
behavior, the results of these works are in line with the experimental data [35-39]. Several works in the literature also present group contribution methods to predict phase envelope or solubility of gases in the heavy fraction of oils $[40,41]$. In this work, it is intended to study the amount of precipitated asphaltene upon pressure drop and also injection of different mole percentages of various gases including $\mathrm{CO}_{2}, \mathrm{~N}_{2}$, and $\mathrm{CH}_{4}$, at different temperatures. The latter is imperative since to the best of our knowledge no research has been conducted to investigate the impact of temperature on asphaltene precipitation. In oil reservoirs, usually, the temperature remains constant but otherwise is expected near the injection well.

A simple and robust algorithm based on Rachford-Rice equation using PC-SAFT EoS for fugacity coefficient calculations is used in this work to eliminate the complexity of asphaltene phase behavior prediction by minimizing the Gibbs free energy of the three-phase system. This algorithm is validated using experimental data of Asphaltene Phase Envelope (APE) upon the injection of different gases at various pressures and temperatures. This simple VaporLiquid-Liquid Equilibrium (VLLE) algorithm may also be used in conjunction with other EOSs. To explain it briefly, at first, a conventional two-phase flash calculation (VLE) is performed. Then, the stationary point method by Michelsen [42] is used to have initial guesses for the stability analysis which is crucial for algorithms in multiphase equilibrium calculations. Stability analysis is done to check the stability of the liquid phase resulted from the VLE. If the presence of a new liquid phase, such as asphaltene phase is verified, the three-phase split calculation is performed next by solving Rachford-Rice equations for the vapor phase and a second liquid phase (asphaltene phase).

\section{Theoretical calculations}

\subsection{PC-SAFT EoS}

In phase equilibrium, the computation of fugacity coefficients of each component is of prime importance. Different EoSs use various methods to calculate the fugacity coefficient. Using PC-SAFT EoS usually includes two stages for thermodynamic equilibrium models: (i) Helmholtz free energy, and (ii) fugacity coefficient calculation. The PC-SAFT EoS is based on Helmholtz free energy. By extending Helmholtz free energy for the fugacity coefficient, the PC-SAFT EoS is then used for thermodynamic equilibrium. The mixture Helmholtz free energy of the non-associating fluid in PC-SAFT EoS is defined as

$$
\begin{gathered}
\tilde{a}^{\mathrm{res}}=\tilde{a}^{\mathrm{hc}}+\tilde{a}^{\mathrm{disp}}, \\
\tilde{a}=\frac{A}{N k T},
\end{gathered}
$$

where $\tilde{a}^{\text {res }}, \tilde{a}^{\text {hc }}, \tilde{a}^{\text {disp }}$ are the residual, hard chain and dispersion contributions for the mixture Helmholtz free energy, respectively. In equation (2), $A$ is Helmholtz free energy, $N$ is the total number of molecules, $k$ is the Boltzmann constant and $T$ is absolute temperature. The PC-SAFT EoS describes the fugacity coefficient $\left(\varphi_{k}\right)$ of component $k$ as

$$
\begin{aligned}
\ln \varphi_{k}= & \tilde{a}^{\mathrm{res}}+(Z-1)+\left(\frac{\partial \tilde{a}^{\mathrm{res}}}{\partial x_{k}}\right)_{T, v, x_{j \neq k}} \\
& -\sum_{j=1}^{N_{c}} x_{j}\left(\frac{\partial \tilde{a}^{\mathrm{res}}}{\partial x_{j}}\right)_{T, v, x_{i \neq j}}-\ln Z,
\end{aligned}
$$

where $Z, x_{k}$ and $v$ are the compressibility factor, the mole fraction of component $k$ and the molar volume, respectively.

\subsection{The hard chain contribution}

Hard sphere and chain formation constitute the hard chain contribution as follows:

$$
\tilde{a}^{\text {hc }}=\bar{m} \tilde{a}^{\text {hs }}-\sum x_{i}\left(m_{i}-1\right) \ln g_{i i}^{\text {hs }}\left(d_{i i}\right),
$$

where $\bar{m}, m_{i}$, and $g_{i i}^{\text {hs }}\left(d_{i i}\right)$ are the mean segment number, the number of segments in a chain of species $i$ in the mixture and the hard-sphere radial distribution function, respectively. The required equations are expressed as:

$$
\begin{gathered}
\bar{m}=\sum x_{i} m_{i}, \\
\tilde{a}^{\text {hs }}=\frac{1}{\xi_{0}}\left[\frac{\xi_{2}^{3}+3 \xi_{1} \xi_{2} \xi_{3}}{\xi_{3}\left(1-\xi_{3}\right)^{2}}-\left(\xi_{0}-\frac{\xi_{2}^{3}}{\xi_{3}^{2}}\right) \ln \left(1-\xi_{3}\right)\right], \\
\xi_{n}=\left(\frac{\pi}{6} \rho\right) \sum\left(x_{i} m_{i} d_{i i}^{n}\right) \quad n=0,1,2,3, \\
g_{i i}^{\text {hs }}\left(d_{i j}\right)=\left[\frac{1}{1-\xi_{3}}+\left(\frac{d_{i} d_{j}}{d_{i}+d_{j}}\right) \frac{3 \xi_{2}}{\left(1-\xi_{3}\right)^{2}}\right. \\
\left.+2\left(\frac{d_{i} d_{j}}{d_{i}+d_{j}}\right)^{2} \frac{\xi_{2}^{2}}{\left(1-\xi_{3}\right)^{3}}\right] \\
d_{i}=\sigma_{i}\left[1-0.12 \exp \left(-3 \frac{\varepsilon_{i}}{k T}\right)\right]
\end{gathered}
$$

where $\rho$ is the total number density of molecules, $d_{i}$ is the temperature-dependent segment diameter of component $i, \sigma_{i}$ is the temperature independent segment diameter and $\varepsilon_{i}$ is the depth of square well potential of component $i$.

\subsection{The dispersion contribution}

There are attractive forces between molecular segments that interact with each other. The attractive forces between 
chains with the same and different lengths are defined as dispersion contribution using the following equations:

$$
\begin{aligned}
\tilde{a}^{\text {disp }}= & -2 \pi \rho I_{1}(\eta, \bar{m}) \overline{m^{2} \varepsilon \sigma^{3}} \\
& -\pi \rho \bar{m} C_{1} I_{2}(\eta, \bar{m}) \overline{m^{2} \varepsilon^{2} \sigma^{3}},
\end{aligned}
$$

where the variables $C_{1}, \overline{m^{2} \varepsilon \sigma^{3}}$, and $\overline{m^{2} \varepsilon^{2} \sigma^{3}}$ are described as

$$
\begin{gathered}
C_{1}=\left[1+\bar{m} \frac{8 \eta-2 \eta^{2}}{(1-\eta)^{4}}+(1-\bar{m}) \frac{20 \eta-27 \eta^{2}+12 \eta^{3}-2 \eta^{4}}{[(1-\eta)(2-\eta)]^{2}}\right]^{-1} \\
\overline{m \varepsilon \sigma^{3}}=\sum_{i}^{N} \sum_{i}^{N} x_{i} x_{j} m_{i} m_{j}\left(\frac{\varepsilon_{i j}}{k T}\right) \sigma_{i j}^{3} \\
\overline{m^{2} \varepsilon^{2} \sigma^{3}}=\sum_{i}^{N} \sum_{i}^{N} x_{i} x_{j} m_{i} m_{j}\left(\frac{\varepsilon_{i j}}{k T}\right)^{2} \sigma_{i j}^{3}
\end{gathered}
$$

where $\eta$ is the packing fraction (reduced density), which is equal to $\xi_{3}[18,34]$. Other equations for calculation of required derivatives such as $\left(\frac{\partial \tilde{a}^{\mathrm{res}}}{\partial x_{k}}\right)_{T, v, x_{j \neq k}}$ and $\left(\frac{\partial \tilde{a}^{\mathrm{res}}}{\partial x_{j}}\right)_{T, v, x_{i \neq j}}$ are given elsewhere $[18,43]$.

\section{Oil characterization for PC-SAFT EoS}

The PC-SAFT EoS needs five parameters of fluid characterization: (1) the number of segments in the molecule (i.e., chain length), $m,(2)$ a size parameter, $\sigma,(3)$ a segment energy parameter, $\varepsilon,(4)$ the volume of association, $\kappa^{\mathrm{AiBi}}$, and (5) the energy of association, $\varepsilon^{\mathrm{AiBi}}$. The last two parameters are required only for the molecules that are selfassociating. Previous studies have shown that asphaltene phase stability is controlled by van der Waals forces, hence $m, \sigma$ and $\varepsilon$ are enough for modeling asphaltene phase behavior $[27,32]$. These parameters are in general obtained based on regression to vapor pressure and saturated liquid densities for pure components [34].

Two asphaltenic oil samples "A" and "B" were studied in this work. They were taken from reservoirs that experienced asphaltene precipitation problem during primary oil recovery [44]. The composition and PC-SAFT parameters of these oil samples are given in Tables 1 and 2, respectively. Experimental studies were implemented by Jamaluddin et al. [44] to evaluate asphaltene precipitation from crude oil "A" under $\mathrm{N}_{2}$ injection [44], also, they characterized this oil as a recombined oil to obtain PC-SAFT EoS parameters $[35,45]$. They considered the separator gas as a fourcomponent fluid (i.e., $\mathrm{N}_{2}, \mathrm{CO}_{2}, \mathrm{C}_{1}$, and light $n$-alkanes) and recombined it with the stock tank oil which was characterized by three sub-fractions of saturates, aromatics plus resins and asphaltenes. They used PC-SAFT EoS and modeled this crude oil APE. Gonzalez et al. [45] showed that the experimental data of asphaltene precipitation for crude oil "A" [44] are well described by the PC-SAFT EoS model. For oil "B" the composition of mono-phasic reservoir fluid is available. Hence, Tavakkoli et al. [46] flashed it to atmospheric conditions by PC-SAFT EoS to obtain flashed gas and liquid compositions. They recombined these compositions and tuned the aromaticity value $(\gamma)$ for $\mathrm{C}_{7+}$ and $n$-hexane to find the characterized composition of oil "B" for the PC-SAFT equation. PC-SAFT parameters of all of the components of oil "B" after characterization are reported in Table 2. Binary interaction coefficients are available in the main references $[45,46]$.

Tavakkoli et al. [46] divided the asphaltene fraction into two sub-fractions of $n-\mathrm{C}_{5-7}$ and $n-\mathrm{C}_{7+}$ asphaltenes, based on the experimental amount of asphaltenes precipitated by $n-\mathrm{C}_{5}$ and $n-\mathrm{C}_{7}$ to investigate the effect of asphaltene polydispersity. They fitted the aromaticity value for the aromatics + resins component to reproduce both the experimental stock tank oil density and bubble point pressure. The aromaticity value and molecular weight of asphaltene subfractions are fitted to the experimental upper onset pressure at different temperatures. Aromaticity values are reported in Table 2 for oil "B". To highlight the diverse impact of gas injected to the reservoir on the drop-out curve of asphaltene, in this study, we predicted the amount of asphaltene that precipitates upon the injection of different gases under wellbore operating conditions. We also studied the effect of change in the temperature near the wellbore. The asphaltene drop out curves for oil with and without different gases is regenerated in this research assuming that the precipitation occurs in the Liquid-Liquid Equilibrium (LLE) between the upper onset and bubble point region and VLLE between the bubble point and lower onset pressure. This study proves that careful scrutiny is essential for EOR/IOR methods which involve additional gas.

\section{Results and discussion}

Figure 1 shows the APE for the crude oil "A". To interpret this figure, one needs to check the asphaltene solubility parameter. The solubility parameter given by Hildebrand is calculated by $\delta=\left(-U^{r} / v_{m}\right)^{0.5}$ [47]. This parameter is the square root of Cohesive Energy Density (CED), the term in parentheses, is the energy required for removing a molar volume of the component from its neighbors to infinite separation. This relation is often used for nonpolar and slightly polar systems with no hydrogen bonding. It is worth mentioning that asphaltene has the highest solubility parameter among the components of crude oil [48]. Decreasing the pressure increases the molar volume and hence, lowers the asphaltene solubility. Asphaltene starts to precipitate at an upper onset pressure and reaches its maximum around the bubble pressure. For pressures below the bubble point, lighter components are released by which the molar volume of the liquid phase drops and consequently asphaltene solubility increases. Then, precipitation of asphaltene stops at a pressure called lower onset pressure. Temperature changes may have two diverse effects on the APE of crude oils. Higher temperature results in higher molar volumes and higher oil entropy. The overall decrease or increase in CED is determined by a competitive increase in numerator and denominator of the fraction. At lower 
Table 1. Characterization of crude oil "A" from Gonzalez et al. [45].

\begin{tabular}{|c|c|c|c|c|c|}
\hline Component & MW (g/mole) & $\begin{array}{c}\text { Composition } \\
\text { (mole fraction) }\end{array}$ & $m(-)$ & $\sigma(\mathrm{A})$ & $\varepsilon / k(\mathrm{~K})$ \\
\hline $\mathrm{N}_{2}$ & 28.01 & 0.004950 & 1.2053 & 3.3130 & 90.96 \\
\hline $\mathrm{CO}_{2}$ & 44.01 & 0.145830 & 2.0729 & 2.7852 & 169.21 \\
\hline $\mathrm{CH}_{4}$ & 16.04 & 0.273340 & 1.0000 & 3.7039 & 150.03 \\
\hline Light gases & 44.60 & 0.219170 & 2.0546 & 3.6130 & 204.96 \\
\hline Saturates & 207.60 & 0.238530 & 5.9670 & 3.9320 & 254.05 \\
\hline Aromatics + resins & 270.50 & 0.117500 & 6.4730 & 3.8700 & 332.52 \\
\hline Asphaltenes & 1700.00 & 0.000676 & 29.5000 & 4.3000 & 392.56 \\
\hline
\end{tabular}

Table 2. Characterization of crude oil "B" from Tavakkoli et al. [46].

\begin{tabular}{lccrrr}
\hline Component & MW $(\mathrm{g} /$ mole) & $\begin{array}{c}\text { Composition } \\
\text { (mole fraction) }\end{array}$ & $m(-)$ & $\sigma(\mathrm{A})$ & $\varepsilon / k(\mathrm{~K})$ \\
\hline $\mathrm{N}_{2}$ & 28.01 & 0.005135 & 1.205 & 3.31 & 90.96 \\
$\mathrm{CO}_{2}$ & 44.01 & 0.009468 & 2.073 & 2.78 & 169.21 \\
$\mathrm{CH}_{4}$ & 16.04 & 0.463341 & 1.000 & 3.70 & 150.03 \\
Heavy gases & 43.13 & 0.245650 & 2.017 & 3.60 & 203.90 \\
Saturates & 176.43 & 0.215063 & 5.378 & 3.91 & 250.36 \\
Aromatics + Resins $(\gamma=0.03)$ & 277.00 & 0.060970 & 6.856 & 4.01 & 290.30 \\
$n-\mathrm{C}_{5-7}$ asphaltenes $(\gamma=0.29)$ & 1700.00 & 0.000261 & 32.930 & 4.24 & 353.20 \\
$n-\mathrm{C}_{7}$ asphaltenes $(\gamma=0.29)$ & 2500.00 & 0.000111 & 47.940 & 4.25 & 356.11 \\
\hline
\end{tabular}

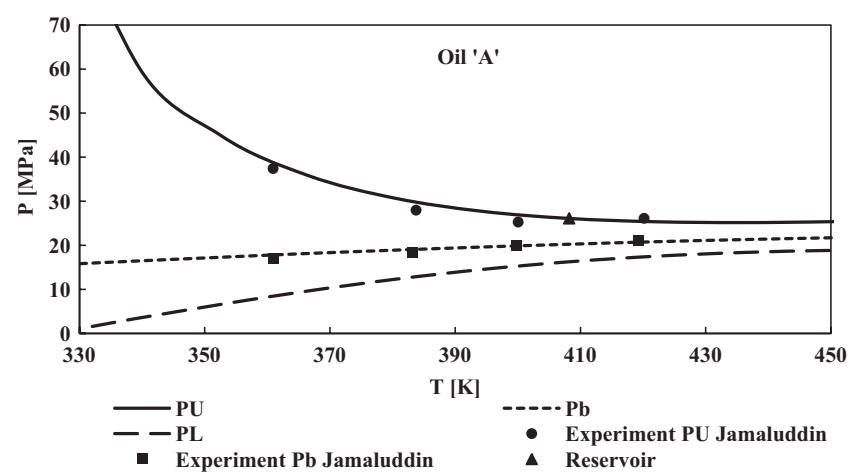

Fig. 1. Comparison of the PC-SAFT model and experimental data [44] for predicting bubble point and asphaltene onset pressures for oil "A" prior to gas injection.

temperatures, the effect of oil entropy is more than density and causes lower solubility for asphaltene, which means lower upper onset and higher lower onset pressures, but at the higher temperature, the oil density effect is prominent.

In Figure 1, Absolute Average Relative Deviations (AARD) for prediction of the upper onset and bubble pressures are $5.36 \%$ and $2.14 \%$, respectively. These values for Figure 2 are $3.63 \%$ and $2.01 \%$, respectively that confirm the applicability of the algorithm used in this work. Figure 3

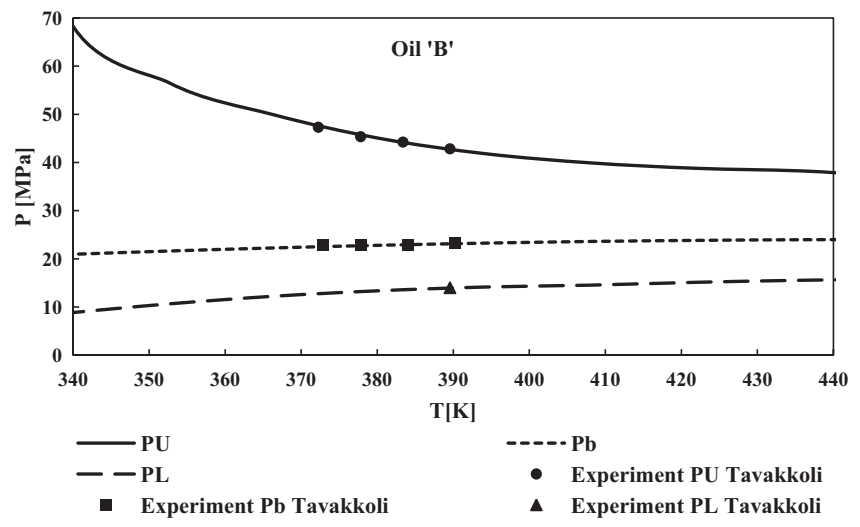

Fig. 2. Comparison of the PC-SAFT model and experimental data [44] for predicting bubble point and asphaltene onset pressures for oil "B" prior to gas injection.

reveals that increasing injection of $\mathrm{N}_{2}$ enhances asphaltene onset pressures, bubble pressures and the difference between the asphaltene onset pressure and the bubble point pressure. This is because of low polarizability and low molecular weight of $\mathrm{N}_{2}$ which cause lower solubility parameter and more asphaltene precipitation and finally the higher difference between upper and lower pressures. In fact, lighter oil has a lower solubility parameter for 


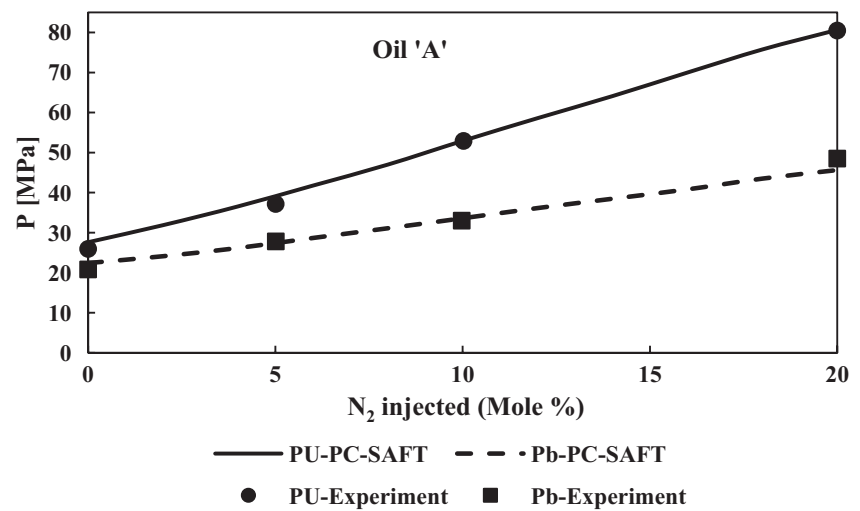

Fig. 3. Comparison of the PC-SAFT model and experimental data [44] for predicting bubble point and asphaltene onset pressure upon the injection of $\mathrm{N}_{2}$ at $420 \mathrm{~K}$ for oil "A".

asphaltene and so produces more asphaltene precipitation. In this figure, AARD values for estimation of upper onset and bubble pressures are $6.75 \%$ and $7.73 \%$, respectively.

As shown in Figures 1-3, a good agreement exists between the model and experimental data for discerning the impact of operational conditions such as temperature, type of injection gas, and the amount of injection gas.

The main parameters that affect the oil APE are $m, \sigma$, and $\varepsilon / k$ of the pseudo-components and their respective binary interaction coefficients with other components. Panuganti et al. [32] and Gonzalez Rodriguez [35] proposed several methods based on sensitivity analysis to fit the experimental data with predictions of the PC-SAFT EoS. The bubble point pressure curve is tuned initially, and then the upper and lower onset curves are matched with the laboratory data by tuning the asphaltene parameters (i.e., $m, \sigma$, and $\varepsilon / k$ ) in their methods. Analyzing the sensitivity of the APE to all of these parameters is beyond the scope of this study. Therefore, we only examined the sensitivity of the APE curves to $m, \sigma$, and $\varepsilon / k$ of asphaltene and the result for crude oil "A" is plotted in Figure 4a-4c, respectively.

\subsection{Effect of injection of various mole fractions of $\mathrm{CO}_{2}$, $\mathrm{CH}_{4}$, and $\mathrm{N}_{2}$ on precipitation of asphaltene}

Figure 5 shows the impact of different mole fractions of $\mathrm{CO}_{2}$ on asphaltene drop-out curve of oil "A" at a typical temperature of the wellbore, $355 \mathrm{~K}$ and $395 \mathrm{~K}$. Comparing Figures $5 \mathrm{a}$ and $5 \mathrm{~b}$ reveals the effect of temperature on the asphaltene drop-out curve due to $\mathrm{CO}_{2}$ injection. In fact, there is a crossover temperature under which $\mathrm{CO}_{2}$ increases crude oil solubility parameters and stabilizes asphaltene that results in a narrower asphaltene drop-out curve as $\mathrm{CO}_{2}$ concentration increases and over which carbon dioxide reduces solubility parameters and makes asphaltene to be unstable at higher pressures. This is shown by calculating the upper onset pressure of asphaltene for oil "A" in Figure 6. This figure depicts that $\mathrm{CO}_{2}$ injection enlarges the APE by elevating the upper onset curve in temperatures a little higher than $370 \mathrm{~K}$. While this curve is dropped at lower temperatures. An expanded APE means when a live oil gets
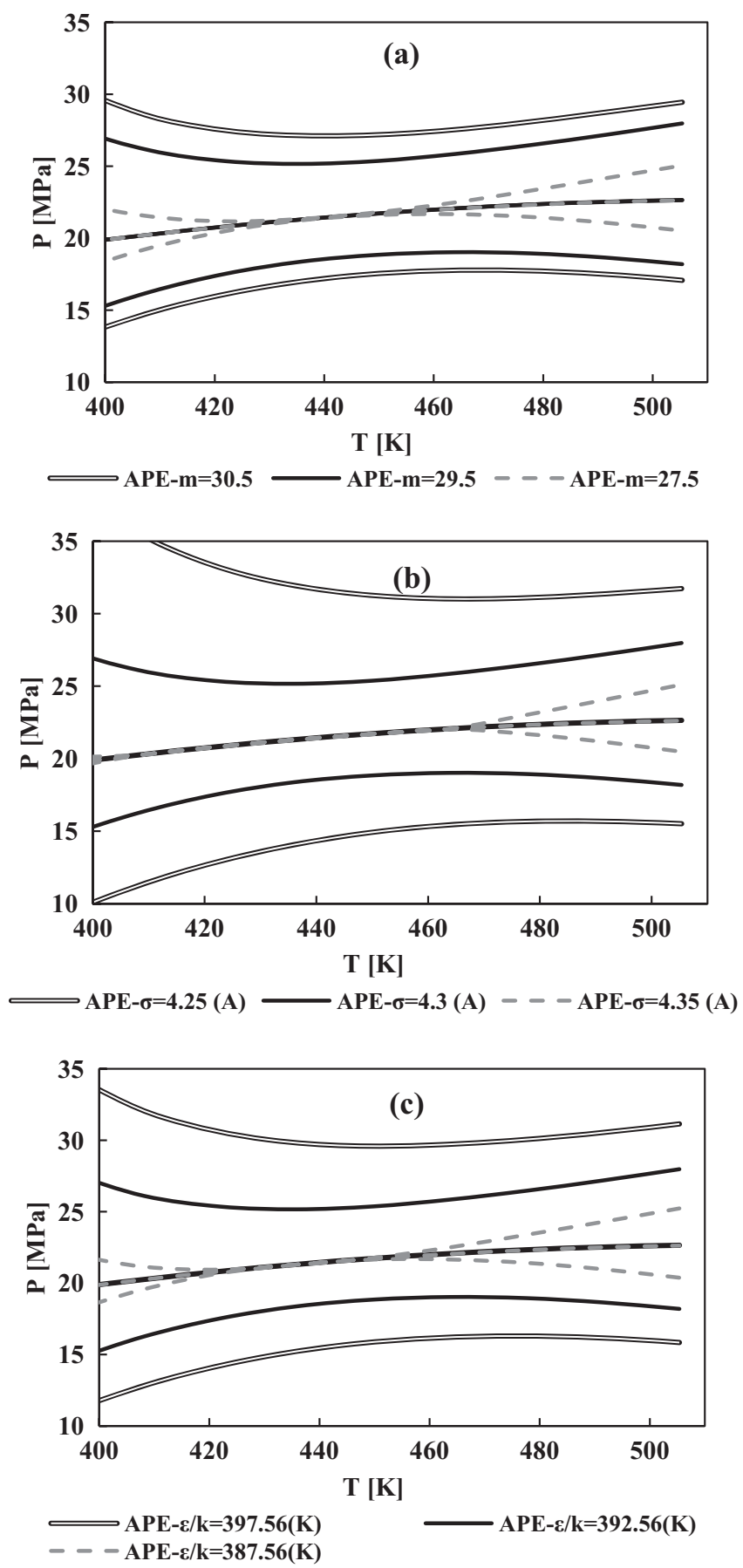

Fig. 4. Sensitivity analysis for asphaltene parameters on APE of crude oil "A". (a): $m,(\mathrm{~b}): \sigma$, and (c): $\varepsilon / k$.

depressurized, asphaltene destabilizes at higher pressures. As shown in Figure 7a, $\mathrm{CO}_{2}$ injection into oil "B" extenuates asphaltene precipitation by making the drop-out curve smaller. The same behavior can be seen in Figure 5a, although adding $\mathrm{CO}_{2}$ to this oil at $395 \mathrm{~K}$ shows a different influence. Increasing the mole percent of $\mathrm{CO}_{2}$ injected to Oil "B" does not give a monotonic increase of upper onset pressure in contrary to the addition of $\mathrm{CO}_{2}$ into oil "A" at $395 \mathrm{~K}$ that grows the upper onset pressure continuously. Thus, the 

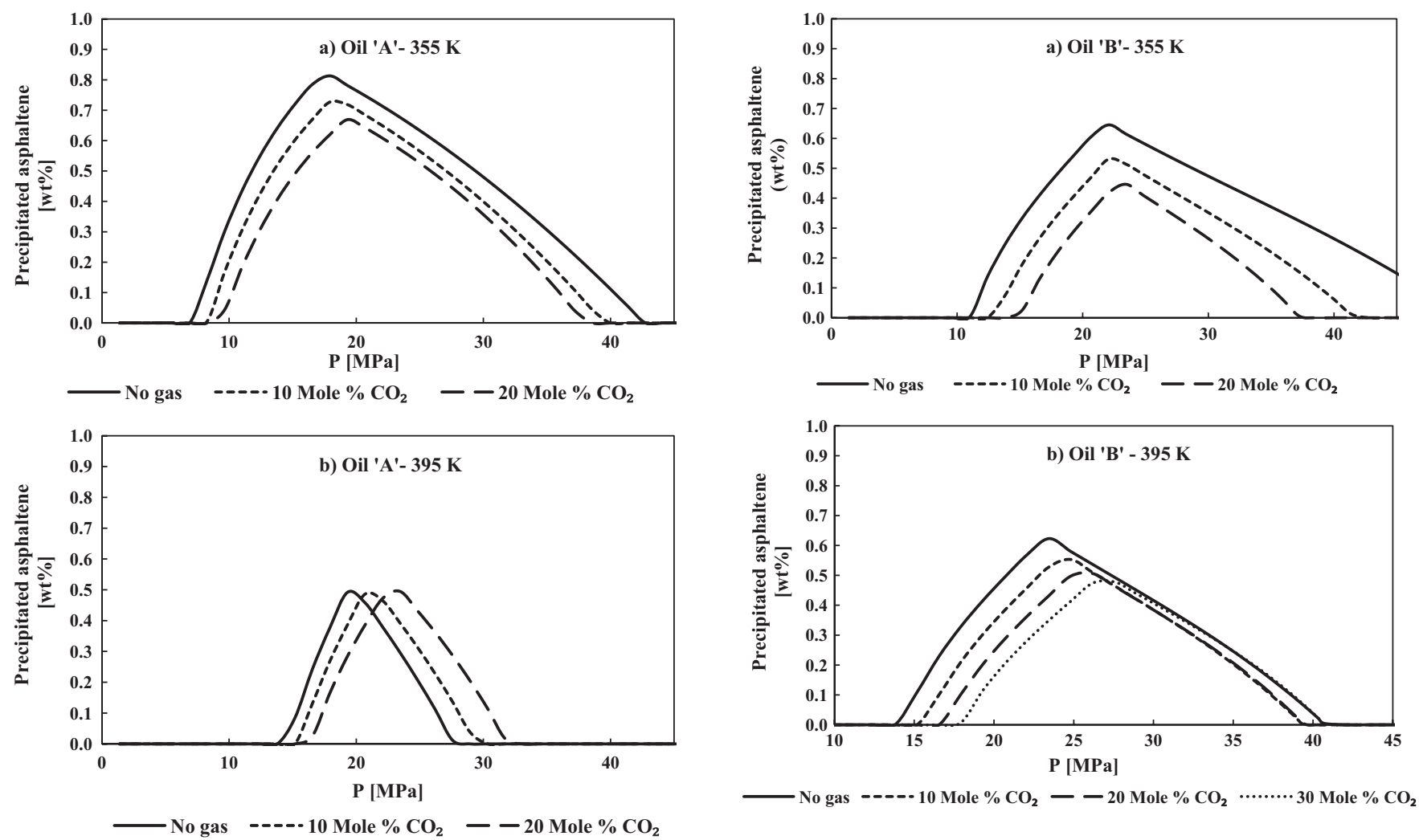

Fig. 5. The amount of asphaltene precipitation for oil "A" upon injection of various mole fractions of $\mathrm{CO}_{2}$ at (a) $T=355 \mathrm{~K}$ and (b) $T=395 \mathrm{~K}$.

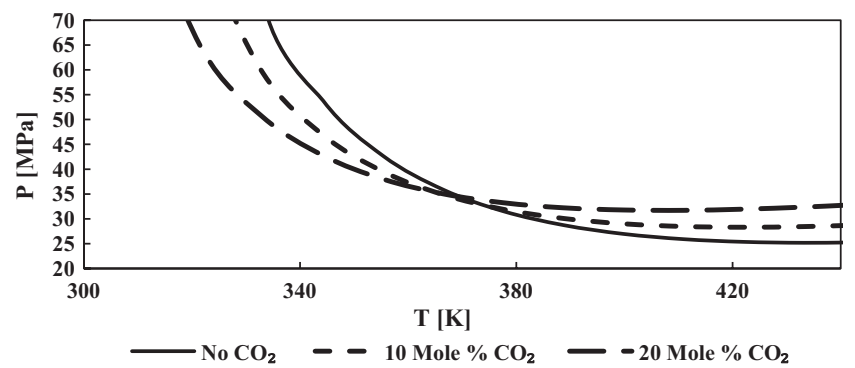

Fig. 6. Effect of $\mathrm{CO}_{2}$ on the APE for crude oil "A".

$\mathrm{CO}_{2}$ injection effect on asphaltene is a function of oil type and reservoir temperature.

Figure 8 clearly shows that $\mathrm{CO}_{2}$ injection decreases and then increases the upper onset curve of asphaltene for oil "B" at $395 \mathrm{~K}$. Although a monotonic decrease in the upper onset pressure is seen at $355 \mathrm{~K}$.

$\mathrm{CH}_{4}$ injection displaces the bubble point and upper onset pressures more sharply in comparison with $\mathrm{CO}_{2}$. Results of this injection for both oils at $355 \mathrm{~K}$ are drawn in Figure 9. This effect is more severe in the case of $\mathrm{N}_{2}$ injection that is depicted in Figure 10. As more $\mathrm{CH}_{4}$ and $\mathrm{N}_{2}$ are injected, higher upper onset pressures and bubble pressures are observed. Nonetheless, for the $\mathrm{CO}_{2}$ injection scenario at

Fig. 7. The amount of asphaltene precipitation for oil "B" upon injection of various mole fractions of $\mathrm{CO}_{2}$ at (a) $T=355 \mathrm{~K}$ and (b) $T=395 \mathrm{~K}$.

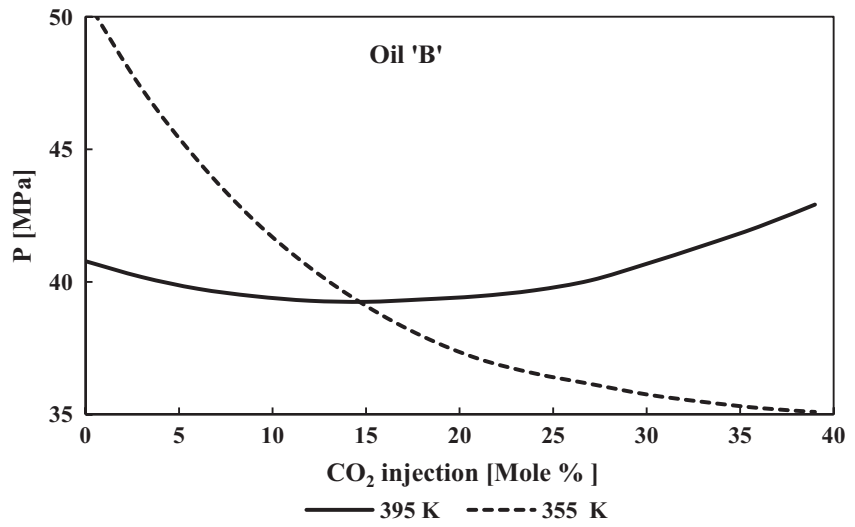

Fig. 8. Effect of $\mathrm{CO}_{2}$ on the upper onset curve of oil "B" at $395 \mathrm{~K}$ and $355 \mathrm{~K}$.

$355 \mathrm{~K}$, its behavior was different. Moreover, the quantities of increased bubble point and upper onset pressures upon $\mathrm{N}_{2}$ injection are more than the cases of $\mathrm{CH}_{4}$ injection. This can be attributed to the density and polarizability of the injected gases.

Adding $\mathrm{N}_{2}$ to the oil lowers the internal energy of the whole system based on Hildebrand solubility parameter and so decreases the asphaltene solubility parameter. This would, in turn, lead to more asphaltene precipitation. The knowledge of bubble point and asphaltene onset pressures 


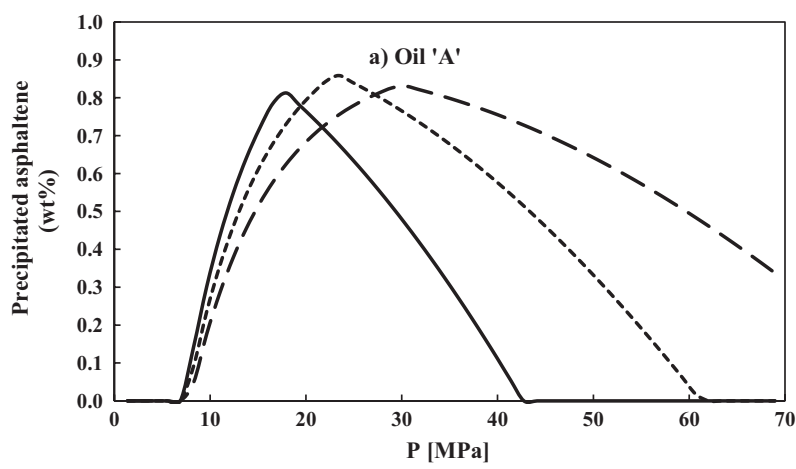

- No gas - - 10 Mole $\% \mathrm{CH}_{4} \quad--20$ Mole $\% \mathrm{CH}_{4}$

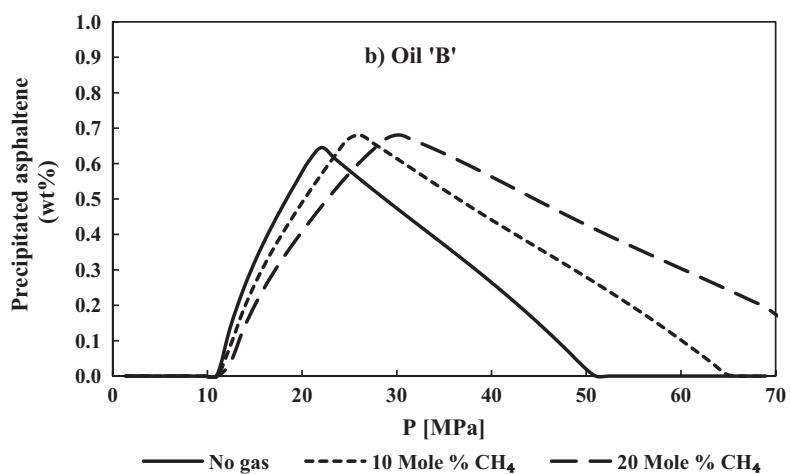

Fig. 9. The amount of asphaltene precipitation upon injection of various mole fractions of $\mathrm{CH}_{4}$ into oils "A" and "B" at $T=355 \mathrm{~K}$.
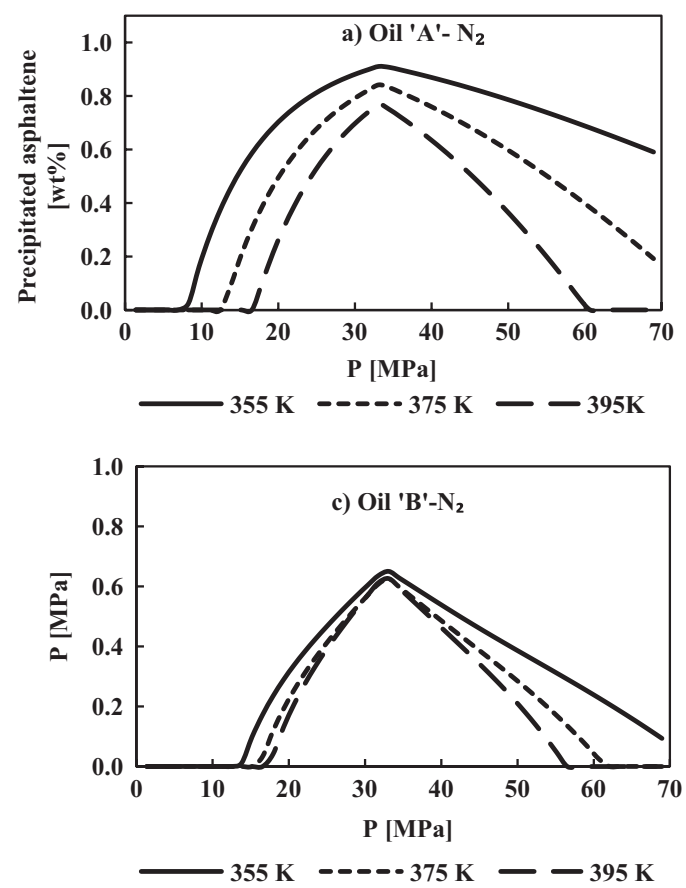

Fig. 10. The amount of asphaltene precipitation upon the injection of various mole fractions of $\mathrm{N}_{2}$ into oils "A" and "B" at $T=355 \mathrm{~K}$.

Fig. 11. The amount of asphaltene precipitation upon injection of 10 mole $\%$ of $\mathrm{CH}_{4}$ and $\mathrm{N}_{2}$ into oils "A" and "B" at different temperatures. 

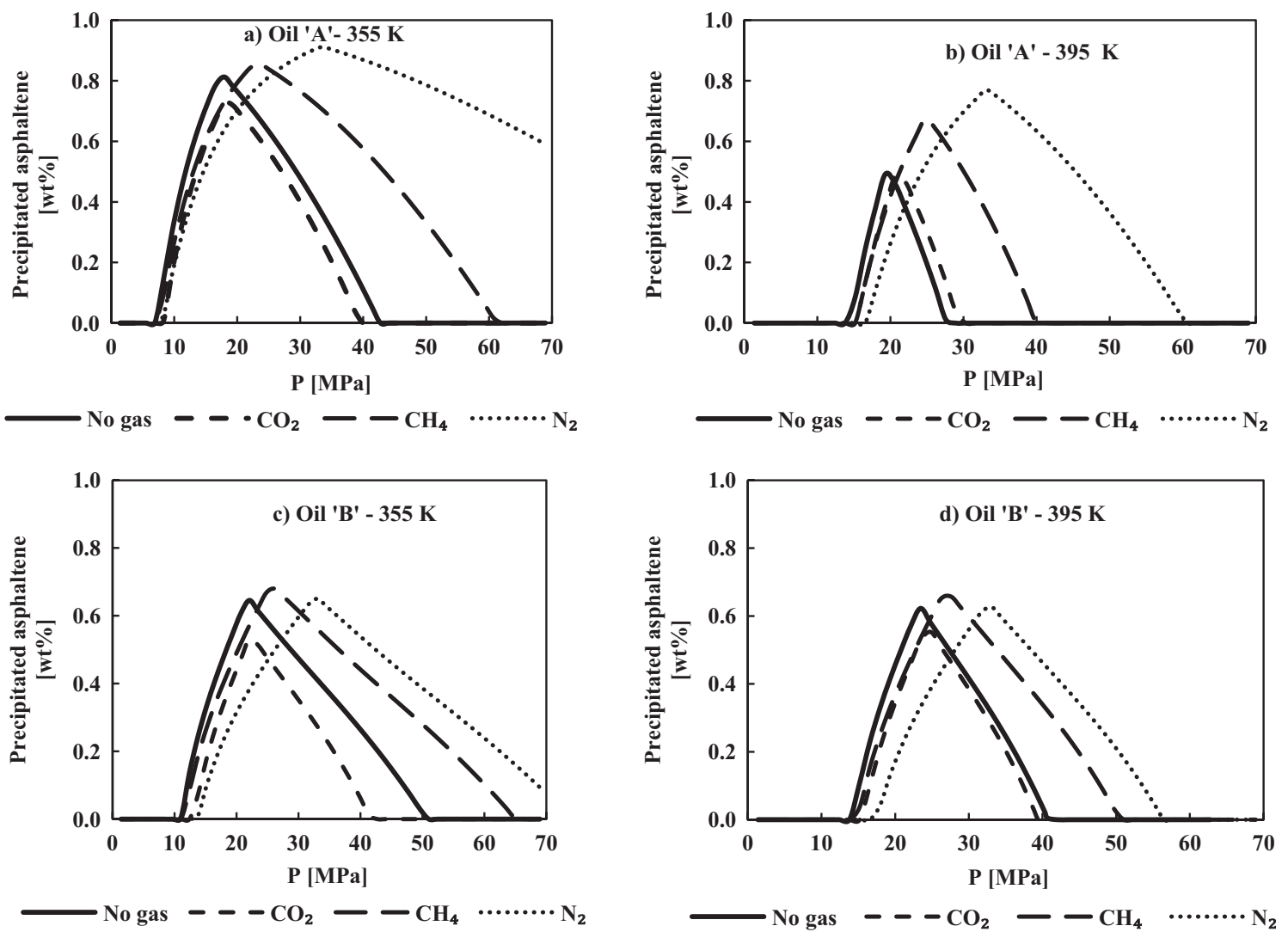

Fig. 12. Precipitation of asphaltene upon injection of 10 mole $\%$ of different gases at $355 \mathrm{~K}$ and $395 \mathrm{~K}$ into oils "A" and "B".

is important to prevent two and three phase flows near the wellbore when the asphaltene would drop out of the liquid phase.

\subsection{Effect of temperature on precipitation of asphaltene due to the injection of various gases}

The temperature change near the wellbore would affect asphaltene precipitation, particularly, during the gas lifting process. Temperature change would have two effects on crude oil. The elevated temperature would result in lower oil density and higher oil entropy. These two effects counteract each other in terms of promoting asphaltene precipitation. Lower oil density causes more asphaltene precipitation, while higher oil entropy causes less asphaltene precipitation. Temperature effect on destabilization of asphaltene during $\mathrm{CO}_{2}$ injection is a matter of debate and needs a precise evaluation of the oil. This was explained earlier in Figures 5-8. As shown in Figure 11, it is obvious that, for $\mathrm{N}_{2}$ and $\mathrm{CH}_{4}$ injection, higher temperature causes a lower amount of asphaltene precipitation. This is because the effect of oil entropy for the temperature range of $355 \mathrm{~K}-395 \mathrm{~K}$ is more pronounced than density, but for various types of injected gas, the effect of temperature on asphaltene precipitation is different. The effect of temperature for $\mathrm{N}_{2}$ injection is more noticeable than for $\mathrm{CH}_{4}$ and $\mathrm{CO}_{2}$.

\subsection{Effect of injected gas type on precipitation of asphaltene at a constant temperature}

To discern the impact of the type of injecting gas on asphaltene precipitation, the calculations were performed using 10 mole $\%$ of different gases at two temperatures. The results are presented in Figure 12. As shown in these figures, $\mathrm{CO}_{2}$ lowers the maximum precipitation of asphaltene in oil "A" at $355 \mathrm{~K}$ by $10.2 \%$ but the effect is very little at $395 \mathrm{~K}$. However, $\mathrm{CH}_{4}$ and $\mathrm{N}_{2}$ intensify the asphaltene precipitation in this type of oil by elevating the maximum drop-out of asphaltene. $\mathrm{CH}_{4}$ and $\mathrm{N}_{2}$ raise the maximum point of the drop out curve by $6.1 \%$ and $12.3 \%$ at $355 \mathrm{~K}$ and by $36.7 \%$ and $57.1 \%$ at $395 \mathrm{~K}$, respectively. The effects are totally different in oil " $\mathrm{B}$ ". $\mathrm{CO}_{2}$ decreases the maximum point at $355 \mathrm{~K}$ and $395 \mathrm{~K}$ by $17.1 \%$ and $11.3 \%$, respectively. $\mathrm{CH}_{4}$ and $\mathrm{N}_{2}$ increase the maximum point by $4.8 \%$ and $4.9 \%$ at $355 \mathrm{~K}$, respectively. $\mathrm{N}_{2}$ does not change the maximum value but displaces it toward higher pressures and $\mathrm{CH}_{4}$ increases it about $5.8 \%$ at $395 \mathrm{~K}$.

\section{Conclusion}

The knowledge of circumstances under which asphaltene starts to precipitate is important to prevent numerous problems associated with this phenomenon. The onset 
and bubble point pressures for the crude oil under study were modeled using PC-SAFT EoS. The results of PC-SAFT EoS correlate accurately with the measured onset pressure and bubble pressures taken from the literature. Furthermore, the fractions of precipitated asphaltene from the oil phase due to the injection of different types of gas at various temperatures were modeled. The following conclusions can be drawn from the results presented in this study:

- No general rule for the effect of the injection of different types of gases into oil was seen in this work. Thus, a detailed evaluation of the oil characteristics is crucial prior to gas injection.

- $\mathrm{CO}_{2}$ injection shows a crossover temperature under which $\mathrm{CO}_{2}$ increases crude oil solubility parameters and over which $\mathrm{CO}_{2}$ reduces the solubility of asphaltene. For temperatures below the crossover temperature, by increasing the mole percent of $\mathrm{CO}_{2}$, asphaltene precipitation decreases.

- $\mathrm{CO}_{2}$ may reduce the size of the drop-out curve or move it toward the higher pressures.

- Injection of $\mathrm{CO}_{2}$ into oil " $\mathrm{B}$ " has a different influence on the variation of upper onset pressure at different temperatures. It decreased and then increased the upper onset pressure at $395 \mathrm{~K}$. However, a monotonic decrease was seen for the upper onset pressure by $\mathrm{CO}_{2}$ injection at $355 \mathrm{~K}$.

- $\mathrm{CH}_{4}$ and $\mathrm{N}_{2}$ expand the drop-out curve by raising the upper onset point. $\mathrm{CH}_{4}$ increases the maximum point of the drop-out curve for both oils at two different temperatures. $\mathrm{N}_{2}$ raises the maximum point of oil "A" by approximately $57 \%$ at $395 \mathrm{~K}$, while it had no effect on the maximum point of oil "B".

- $\mathrm{CH}_{4}$ has widened the drop-out curve by increasing the upper onset pressure and raised up the maximum point of the curve in all cases.

- The higher the temperature, the lower asphaltene precipitation would be expected.

- The effect of nitrogen injection on asphaltene precipitation is higher than other gases examined.

Acknowledgments. The authors are grateful to Dr. M. J. Amani for his technical help over the course of this study.

\section{References}

1 Gonzalez D.L., Hirasaki G.J., Creek J., Chapman W.G. (2007) Modeling of asphaltene precipitation due to changes in composition using the perturbed chain statistical associating fluid theory equation of state, Energy Fuels 21, 12311242.

2 Leontaritis K., Amaefule J., Charles R. (1994) A systematic approach for the prevention and treatment of formation damage caused by asphaltene deposition, SPE Prod. Facil. 9, $157-164$.

3 Mansoori G.A. (1997) Modeling of asphaltene and other heavy organic depositions, J. Pet. Sci. Eng. 17, 101-111.
4 Schou Pedersen K., Hasdbjerg C. (2007) PC-SAFT equation of state applied to petroleum reservoir fluids, in: SPE Annual Technical Conference and Exhibition, Society of Petroleum Engineers.

5 Vargas F.M., Creek J.L., Chapman W.G. (2010) On the development of an asphaltene deposition simulator, Energy Fuels 24, 2294-2299.

6 Speight J. (2004) Petroleum asphaltenes-Part 1: Asphaltenes, resins and the structure of petroleum, Oil Gas Sci. Technol. - Rev. IFP Energies nouvelles 59, 467-477.

7 Groenzin H., Mullins O.C. (2000) Molecular size and structure of asphaltenes from various sources, Energy Fuels 14, 677-684.

8 Boduszynski M. (1979) Asphaltenes in petroleum asphalts: composition and formation, Am. Chem. Soc., Div. Pet. Chem., Prepr. (United States) 24.

9 Rodgers R.P., Marshall A.G. (2007) Petroleomics: Advanced characterization of petroleum-derived materials by Fourier transform ion cyclotron resonance mass spectrometry (FT-ICR MS), in: Asphaltenes, heavy oils, and petroleomics, Springer, New York, pp. 63-93.

10 Merdrignac I., Desmazieres B., Terrier P., Delobel A., Laprevote O. (2004) Analysis of raw and hydrotreated asphaltenes using off-line and on-line SEC/MS coupling, Proceedings of the Heavy Organic Deposition, Los Cabos, Baja California, Mexico.

11 Qian K., Edwards K.E., Siskin M., Olmstead W.N., Mennito A.S., Dechert G.J., Hoosain N.E. (2007) Desorption and ionization of heavy petroleum molecules and measurement of molecular weight distributions, Energy Fuels 21, 1042-1047.

12 Hortal A.R., Martínez-Haya B., Lobato M.D., Pedrosa J.M., Lago S. (2006) On the determination of molecular weight distributions of asphaltenes and their aggregates in laser desorption ionization experiments, J Mass Spectrometry 41, 960-968.

13 Akbarzadeh K., Hammami A., Kharrat A., Zhang D., Allenson S., Creek J., Kabir S., Jamaluddin A., Marshall A.G., Rodgers R.P. (2007) Asphaltenes - problematic but rich in potential, Oilfield Rev. 19, 22-43.

14 Mullins O.C., Sheu E.Y., Hammami A., Marshall A.G. (2007) Asphaltenes, heavy oils, and petroleomics, Springer Science \& Business Media, New York.

15 Creek J.L. (2005) Freedom of action in the state of asphaltenes: Escape from conventional wisdom, Energy Fuels 19, 1212-1224.

16 Al-Sahhaf T.A., Fahim M.A., Elkilani A.S. (2002) Retardation of asphaltene precipitation by addition of toluene, resins, deasphalted oil and surfactants, Fluid Phase Equilib. 194, 1045-1057.

17 Chang C.-L., Scott Fogler H. (1996) Peptization and coagulation of asphaltenes in apolar media using oil-soluble polymers, Fuel Sci. Technol. Int. 14, 75-100.

18 Mohebbinia S. (2013) Advanced equation of state modeling for compositional simulation of gas floods, Ph.D. dissertation, Petroleum and Geosystems Engineering Department, The University of Texas at Austin.

19 Tabzar A., Fathinasab M., Salehi A., Bahrami B., Mohammadi A.H. (2018) Multiphase flow modeling of asphaltene precipitation and deposition, Oil Gas Sci. Technol. - Rev. IFP Energies nouvelles 73, 51.

20 Bagheri M., Kharrat R., Ghotby C. (2011) Experimental investigation of the asphaltene deposition process during different production schemes, Oil Gas Sci. Technol. - Rev. IFP Energies nouvelles 66, 507-519. 
21 Leontaritis K., Mansoori G. (1987) Asphaltene flocculation during oil production and processing: A thermodynamic collodial model, SPE International Symposium on Oilfield Chemistry, Society of Petroleum Engineers.

22 Pfeiffer J.P., Saal R. (1940) Asphaltic bitumen as colloid system, J. Phys. Chem. 44, 139-149.

23 Boek E.S., Yakovlev D.S., Headen T.F. (2009) Quantitative molecular representation of asphaltenes and molecular dynamics simulation of their aggregation, Energy Fuels 23, 1209-1219.

24 Buckley J., Hirasaki G., Liu Y., Von Drasek S., Wang J., Gill B. (1998) Asphaltene precipitation and solvent properties of crude oils, Pet. Sci. Technol. 16, 251-285.

25 Czarnecki J. (2008) Stabilization of water in crude oil emulsions. Part 2, Energy Fuels 23, 1253-1257.

26 Goual L. (2009) Impedance spectroscopy of petroleum fluids at low frequency, Energy Fuels 23, 2090-2094.

27 David Ting P., Hirasaki G.J., Chapman W.G. (2003) Modeling of asphaltene phase behavior with the SAFT equation of state, Pet. Sci. Technol. 21, 647-661.

28 Flory P.J. (1942) Thermodynamics of high polymer solutions, J. Chem. Phys. 10, 51-61.

29 Hildebrand J.H. (1919) Solubility. III. Relative values of internal pressures and their practical application, J. Am. Chem. Soc. 41, 1067-1080.

30 Scatchard G. (1931) Equilibria in non-electrolyte solutions in relation to the vapor pressures and densities of the components, Chem. Rev. 8, 321-333.

31 Scott R.L., Magat M. (1945) The thermodynamics of highpolymer solutions: I. The free energy of mixing of solvents and polymers of heterogeneous distribution, J. Chem. Phys. 13, 172-177.

32 Panuganti S.R., Vargas F.M., Gonzalez D.L., Kurup A.S., Chapman W.G. (2012) PC-SAFT characterization of crude oils and modeling of asphaltene phase behavior, Fuel 93, 658-669.

33 Chapman W.G., Gubbins K.E., Jackson G., Radosz M. (1990) New reference equation of state for associating liquids, Ind. Eng. Chem. Res. 29, 1709-1721.

34 Gross J., Sadowski G. (2002) Application of the perturbedchain SAFT equation of state to associating systems, Ind. Eng. Chem. Res. 41, 5510-5515.

35 Gonzalez Rodriguez D.L. (2008) Modeling of asphaltene precipitation and deposition tendency using the PC-SAFT equation of state, PhD dissertation, Rice University, Houston, Texas.

36 Vargas F.M., Gonzalez D.L., Hirasaki G.J., Chapman W.G. (2009) Modeling asphaltene phase behavior in crude oil systems using the perturbed chain form of the statistical associating fluid theory (PC-SAFT) equation of state $\dagger$, Energy Fuels 23, 1140-1146.

37 Panuganti S.R., Tavakkoli M., Vargas F.M., Gonzalez D.L., Chapman W.G. (2013) SAFT model for upstream asphaltene applications, Fluid Phase Equilib. 359, 2-16.

38 Zúñiga-Hinojosa M.A., Justo-García D.N., Aquino-Olivos M.A., Román-Ramírez L.A., García-Sánchez F. (2014) Modeling of asphaltene precipitation from n-alkane diluted heavy oils and bitumens using the PC-SAFT equation of state, Fluid Phase Equilib. 376, 210-224.

39 Sabeti M., Rahimbakhsh A., Nikookar M., Mohammadi A.H. (2015) Estimation of asphaltene precipitation and equilibrium properties of hydrocarbon fluid phases using the PC-SAFT equation of state, J. Mol. Liquids 209, $447-460$.

40 Aguilar-Cisneros H., Uribe-Vargas V., Carreón-Calderón B., Domínguez-Esquivel J.M., Ramirez-de-Santiago M. (2017) Hydrogen solubility in heavy undefined petroleum fractions using group contributions methods, Oil Gas Sci. Technol. - Rev. IFP Energies nouvelles 72, 2.

41 Nasrifar K., Rahmanian N. (2018) Equations of state with group contribution binary interaction parameters for calculation of two-phase envelopes for synthetic and real natural gas mixtures with heavy fractions, Oil Gas Sci. Technol. Rev. IFP Energies nouvelles 73, 7.

42 Michelsen M.L. (1982) The isothermal flash problem. Part I. Stability, Fluid Phase Equilib. 9, 1-19.

43 Privat R., Gani R., Jaubert J.-N. (2010) Are safe results obtained when the PC-SAFT equation of state is applied to ordinary pure chemicals? Fluid Phase Equilib. 295, 76-92.

44 Jamaluddin A., Joshi N., Iwere F., Gurpinar O. (2002) An investigation of asphaltene instability under nitrogen injection, Society of Petroleum Engineers, Mexico.

45 Gonzalez D.L., Ting P.D., Hirasaki G.J., Chapman W.G. (2005) Prediction of asphaltene instability under gas injection with the PC-SAFT equation of state, Energy Fuels 19, 1230-1234.

46 Tavakkoli M., Panuganti S.R., Taghikhani V., Pishvaie M.R., Chapman W.G. (2013) Precipitated asphaltene amount at high-pressure and high-temperature conditions, Energy Fuels 28, 1596-1610.

47 Barton A.F.M. (1991) Handbook of solubility parameters and other cohesion parameters, CRC, New York, NY.

48 Wang J.X., Buckley J.S. (2001) A two-component solubility model of the onset of asphaltene flocculation in crude oils, Energy Fuels 15, 1004-1012. 